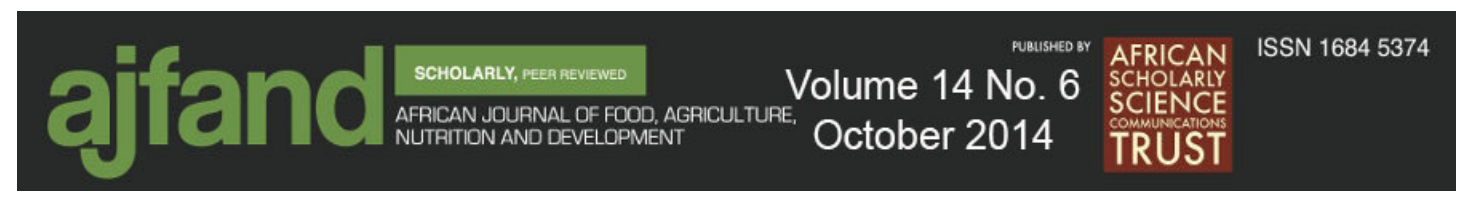

\title{
EFFECT OF CASSAVA FLOUR PROCESSING METHODS AND SUBSTITUTION LEVEL ON PROXIMATE COMPOSITION, SENSORY CHARACTERISTICS AND OVERALL ACCEPTABILITY OF BREAD MADE FROM WHEAT- CASSAVA FLOUR BLENDS
}

Masamba $\mathrm{K}^{\mathbf{1}^{*}}$ and $\mathrm{H}$ Jinazali $^{2}$

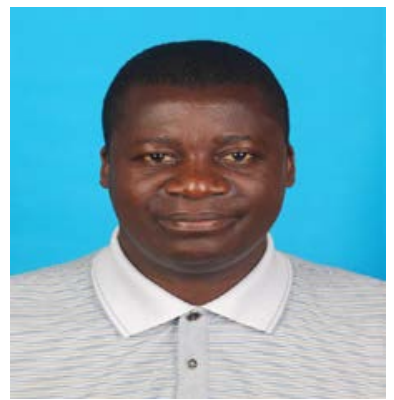

Kingsley Masamba

*Corresponding author: kmasamba@yahoo.com

${ }^{1}$ Senior lecturer, Food Science and Technology, Department of Food Science and Technology, Lilongwe University of Agriculture and Natural Resources (LUANAR), Bunda College Campus, P.O. Box 219, Lilongwe, Malawi Member, Australian Institute of Food Science and Technology

${ }^{2}$ Department of Food Science and Technology, Lilongwe University of Agriculture and Natural Resources (LUANAR), Bunda College Campus, P.O. Box 219, Lilongwe, Malawi. 


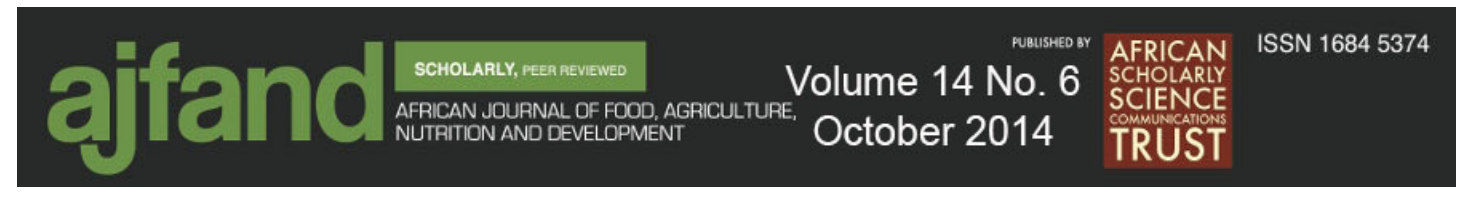

\section{ABSTRACT}

The consumption of bread is globally increasing. However, due to increased costs associated with production of bread from $100 \%$ wheat flour especially in developing countries, other cereal based flours are now being blended with wheat flour to produce bread. This study was carried out to assess the effect of using two differently processed cassava flour (fermented and unfermented) and substitution level on proximate composition, sensory characteristics and overall acceptability of bread made from wheat-cassava flour blends. Bread was made using wheat flour incorporated in fermented and unfermented cassava flour at the ratios of 100:0, 90:10 and 80:20 for wheat: cassava flour, respectively and baked using a Morphy Richards (serial number 20076019) bread maker. The results showed that both the cassava flour and cassava flour substitution levels significantly affected $(\mathrm{p}<0.05)$ proximate composition, sensory characteristics and overall acceptability of the bread. Regardless of flour type, increased cassava flour substitution progressively decreased the crude protein and fat contents while the ash content was increased. The trend in significant differences as a reflection of the effect of cassava flour type and substitution level for the bread sensory characteristics was not consistent. Bread made from the $100 \%$ wheat flour was not significantly different from breads made from the following cassava flour type and substitution levels: 10\% fermented cassava flour, $10 \%$ unfermented flour and 20\% unfermented cassava flour in colour, texture, aroma and taste. Significant differences were observed between bread made from the $100 \%$ wheat flour and breads from the following cassava type and substitution levels: $20 \%$ fermented cassava flour, $10 \%$ and $20 \%$ unfermented cassava flour in colour, texture, aroma and taste. Overall acceptability and index to volume were both significantly affected by the cassava flour type and substitution levels. In conclusion, cassava flour substitution levels in wheat-cassava flour blends for bread making should not exceed $10 \%$ regardless of how the cassava flour has been processed to ensure bread with improved proximate composition and acceptable sensory attributes.

Key words: bread, acceptability, proximate, sensory, cassava 


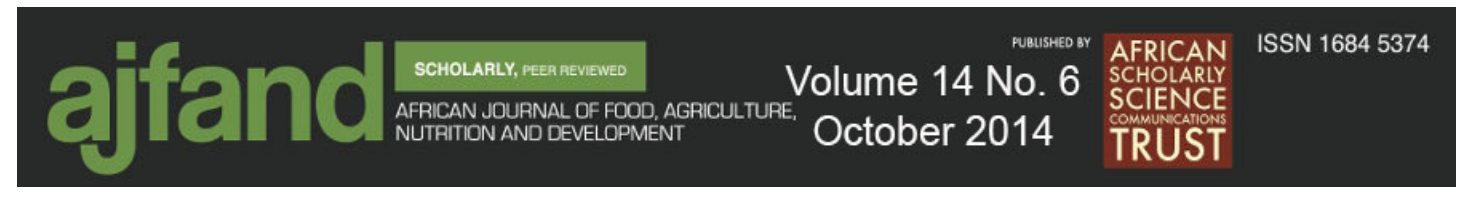

\section{INTRODUCTION}

Wheat flour is the main cereal crop used for baking different products such as bread primarily because of its high gluten content and production of different baked products can be done at both household and industry level. Wheat is one of the world's major cereals and is suitable for bakery products because it has a bland flavour [1]. Wheat is most adapted to temperate climate. In Africa, it is mostly successfully grown in cool season when temperatures do not exceed $25^{\circ} \mathrm{C}$ and the humidity is low. Wheat grain is rich in protein $(12.7 \mathrm{~g} / 100 \mathrm{~g})$, fat $(2.2 \mathrm{~g} / 100 \mathrm{~g})$, iron (3.5mg/100g), calcium and several of B vitamins such as thiamine $(0.40 \mathrm{mg} / 100 \mathrm{~g})$, niacin (5.0/100g) and riboflavin $(0.17 \mathrm{mg} / 100 \mathrm{~g})$ [2]. On the other hand wheat is poor in vitamins $\mathrm{A}$ (trace), D and C. Thus, they have to be supplemented by other flours in the diet.

Incorporation of different proportions of flours from cereals and legumes in baked products such as bread is extensively being studied especially in developing countries. Cassava flour is used with wheat flour in bread making and more research is ongoing to improve the bread characteristics from different cassava processing methods and assessing the adoption requirements [3]. Cassava flour is variedly processed in different parts of Malawi. The cassava flour in the lakeshore district of Nkhata bay is processed from sun dried tubers which have been fermented for 4-7 days while in the southern districts of Thyolo and Mulanje, the flour is usually processed from unfermented sliced tubers which are ground into flour after being sun dried. The available literature on cassava flour use in bread making especially in Malawi suggest limited research work on how cassava flour substitution in wheat flour may affect proximate composition, sensory characteristics and overall acceptability of bread.

The current study was therefore carried out to assess the effect of two differently processed cassava flour types namely fermented and unfermented flour and cassava substitution level on proximate composition, sensory characteristics and overall acceptability of bread made from wheat-cassava flour blends.

\section{MATERIALS AND METHODS}

\section{Raw materials collection}

The cassava tubers used in the study were purchased from the local farmers from villages surrounding Bunda College of Agriculture. Consideration was made to purchase one single local variety from the local farmers to minimize variations which might be attributed to cassava variety. All the other ingredients required for bread making like bread wheat flour, sugar, yeast, salt and margarine were purchased from local markets within Lilongwe city.

\section{Cassava tuber preparation and flour processing}

The tubers were thoroughly washed to remove the adhering soils and the outer layers were peeled off using knives and subsequently processed in two ways. For unfermented cassava flours, the peeled tubers were grated using a traditionally improvised grater. The grated pieces were sun dried on mats until they become brittle 


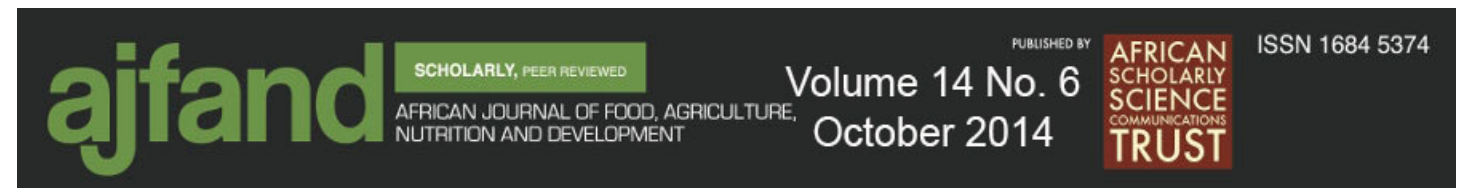

and then they were milled into flour using a hammer mill. For the fermented cassava flour, the peeled tubers were soaked in buckets containing water for 7 days and thereafter, they were thoroughly washed, sun dried and ground into flour prior to use.

\section{Proportions of wheat and cassava flour in bread making}

Different proportions of wheat and cassava flour were used in the bread making and included the following proportions for wheat-cassava flour blends: 100:0, 90:10, 80:20. Bread was baked using a Morphy Richards bread maker (Serial number 20076019). The amounts of ingredients to be used in the bread making were specified by the bread maker operating manual. All the specified amounts of the ingredients in the following sequence: water, milk, sugar, salt, margarine, wheat flour, cassava flour and yeast were fed to the bread maker and the whole process from mixing, dough rising and dough baking took approximately 3 hours.

\section{Sample preparation for nutrient and ash content analysis}

The different representative samples of bread made from the different variations (cassava flour type and substitution levels) were cut into slices of 2-3 cm thick. The slices were spread on paper and let to dry at the prevailing ambient room temperatures which were ranging from $25-27^{\circ} \mathrm{C}$ until sufficiently crisp and brittle to grind well in a mill. The sample was ground to pass No. 20 sieve and mixed well and kept in air-tight containers prior to use.

\section{Proximate composition analysis}

All the nutrient and ash content analysis were done according to the Association of Official Analytical Chemists protocol [4, 5, 6]. Crude fat and ash contents were determined by Soxhlet extraction method and ashing by incinerating in the muffle furnace for 5 hours at $500^{\circ} \mathrm{C}$ respectively. Protein content was determined by Kjeldahl method while moisture content was determined by oven drying at $150^{\circ} \mathrm{C}$ for one hour.

\section{Sensory characteristics, index to volume and acceptability evaluation}

Evaluation of sensory characteristics and acceptability were determined using appropriate descriptions with well-defined numbering scores for colour, texture, aroma, taste and the seven-point food action rating scale for acceptability. Index to volume was measured in millimetres by piercing the bread with a small wooden stick in five different points of bread and averaged the total five depth measurements using a ruler. Sensory characteristics evaluation involved descriptive analysis of the sensory attributes under consideration. Semi trained panellists (40) mainly consisting of college students and members of staff from Bunda College assessed the overall acceptability of bread using the seven point food action rating scale [7]. For descriptive analysis, 10 trained panellists were used to evaluate colour, texture, aroma and taste with a scale of 1-5 comprising of appropriate descriptions reflecting the desirability of the sensory attributes under consideration. 


\section{Statistical analysis}

All proximate composition and descriptive sensory data were analyzed using Genistat $12^{\text {th }}$ Edition, where analysis of variance (ANOVA) was used to compare means and Least Significance Difference (LSD) was used to separate and differentiate means $(\mathrm{p}<0.05)$. Data from acceptability sensory scores were analyzed using Statistical Package for Social Scientists (SPSS) for windows version 12.0 and index to volume data was analyzed using Microsoft Excel.

\section{RESULTS}

\section{Bread top surface colour and texture}

The results on bread colour and texture are presented in Table 1 . There were no significant differences in colour and texture between control sample and bread from $10 \%$ substituted fermented cassava flour. Furthermore, it was found out that texture of the control sample was not significantly different from bread made from $10 \%$ and $20 \%$ substituted non fermented cassava flour. However, it was observed that bread made from the $100 \%$ wheat flour or control sample was significantly different with breads from $20 \%$ substituted fermented cassava flour and $10 \%$ and $20 \%$ substituted non fermented cassava flour.

\section{Bread aroma and taste}

The results for aroma and taste are presented in Table 2. The aroma and taste of bread made from the $100 \%$ wheat flour was comparable to the bread made from the substitution levels of $10 \%$ fermented and $20 \%$ non-fermented cassava flour. However, significant differences were observed in bread made from the $100 \%$ wheat flour when compared with breads made from $20 \%$ substituted fermented cassava flour and $10 \%$ substituted non fermented cassava flour. The results also showed that both cassava flour type and substitution level significantly affected aroma and taste of the bread.

\section{Proximate composition}

The results for proximate composition are presented in Table 3. Protein and fat contents were significantly affected by cassava flour type and substitution level while no significant difference was observed in moisture and ash contents. Increased cassava flour substitution levels irrespective of type decreased protein and fat contents. On the other hand, an increase in cassava flour substitution levels irrespective of type increased ash content.

\section{Acceptability and index to volume}

Acceptability and index to volume scores are presented in Table 4. Both cassava flour type and substitution level significantly affected $(\mathrm{p}<0.05)$ acceptability and index to volume scores. Higher acceptability and index to volume scores were obtained in bread made from $100 \%$ wheat flour than in substituted fermented and non-fermented cassava flour and increased cassava flour substitution levels resulted in decreased scores. However, index to volume scores were high in bread made from substituted fermented cassava flour than in substituted non fermented cassava flour regardless of the substitution levels. 


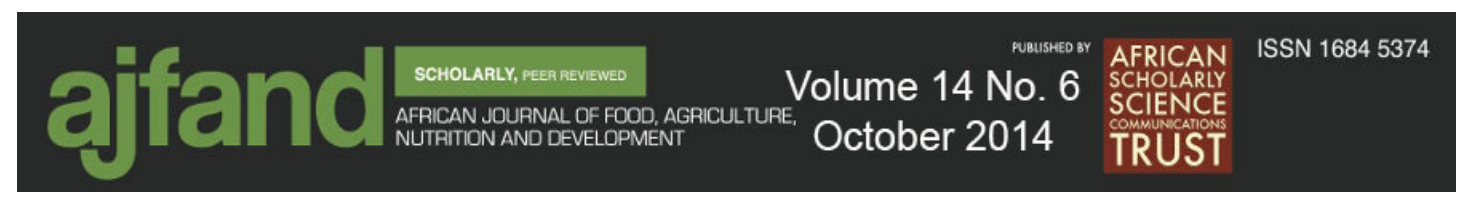

\section{DISCUSSION}

\section{Bread colour and texture}

The results on top surface colour of the bread and bread crust texture showed that they were significantly affected by the cassava flour processing methods and the rate of substitution of cassava flour in the wheat-cassava flour blends for making the bread. The results showed that as more cassava flour was being substituted in wheat-cassava flour blends, the intensity of browning was increasingly becoming less and the bread made from the $100 \%$ wheat flour was browner than the other types of the breads. This was expected since the reduced amount of proteins in the breads made from different proportions of the wheat: cassava flour blends meant reduced proteins in the Maillard reactions which is one of the reactions responsible for brown colour. However, these findings are inconsistent with other similar studies where it was reported that cassava flour supplementation in composite bread did not reduce the caramelization process which forms the brown colour during baking [8]. It was further observed that there were no significant differences in colour of the top surface of bread made from $100 \%$ wheat flour and the bread made from 90\%:10\% wheat-fermented cassava flour blends. The intensity of the browning followed a trend where the higher the colour scores corresponded with increased colour (brown) intensity. The bread crust texture was significantly affected by the type of cassava flour and the substitution rate in the wheat-cassava flour blend used in the making of the bread. For texture, lower scores signified more tenderness. The crust texture varied from moderately tender to moderately tough. The results on crust texture are consistent with findings which reported that if pure starch from another cereal or tuber is used, the product is considerably more rigid and its texture is irregular because gases are insufficiently retained in the dough [9]. Significant differences were observed in breads made from $100 \%$ wheat flour and the one with substitution of $20 \%$ fermented cassava flour. However, there were no significant differences between bread made from $100 \%$ wheat flour and the one with a substitution of $20 \%$ non-fermented cassava flour. The results on texture of the bread crust are also in agreement with previous related studies although in one of the studies the effect of cassava flour processing method on texture was not considered and included other factors such as baking time [10,11]. Results on colour and texture were also consistent with findings by other researchers who used wheat-grain amaranthus flour blends in making bread [12].

\section{Bread aroma and taste}

Significant differences were observed in aroma and taste of the breads produced from the two differently processed cassava flours and using different substitution rates of cassava flour in the wheat-cassava flour blends. The trend in both taste and aroma showed the two sensory parameters were favourably scored in breads produced from reduced amounts of cassava flour. However, the trend of significant differences was not consistent in all the types of bread. It was noted that there were significant differences in aroma of bread made from $100 \%$ wheat flour and the one with $20 \%$ substitution of fermented cassava flour while no significant differences were observed for bread made with $100 \%$ wheat flour, $10 \%$ and $20 \%$ non-fermented cassava flour as 


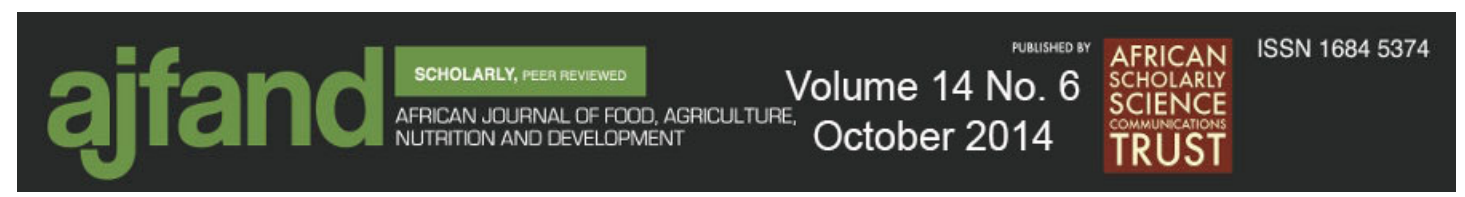

shown in Table 2. A similar observation was also found in a related study where it was concluded that there was a general decrease in sensory scores such as aroma with increase in the supplementation level with cassava flour [13]. Similarly, it was observed that there were also significant differences in taste for bread made from $100 \%$ wheat flour and that made with substitution of $20 \%$ fermented cassava flour. However, it was further noted there were no significant differences from bread made from $100 \%$ wheat flour and the bread made with $10 \%$ substitution of fermented cassava flour and this observation is in agreement with previous findings on a related study which reported that taste was not affected by the level of cassava flour substitution [14]. It was additionally noted that there were some inconsistencies in the results trend which could be attributed to challenges posed in sensory evaluation studies since data collected from human beings are generally known to vary due to anticipated difficulties in understanding and interpreting of terms in descriptive analysis. Furthermore, some researchers have reported that traditional judging methods have several shortcomings such as difficulties in assigning quantitative scores and thus by using traditional methods, some products with very different sensory characteristics, such as those identified by a product flavour profile, but with no product defect will obtain the same quality score [15].

\section{Proximate composition}

The results on proximate composition of the breads showed that different parameters were affected differently by the type of the cassava flour used and the substitution rate of cassava flour in the wheat-cassava flour blends. An increase in the levels of cassava flour regardless of how the cassava flour was processed resulted in progressive decrease in protein and fat contents and this trend is similar to previously conducted studies although in one of the studies cassava flour was supplemented in biscuit making and additionally the composite flour was further enriched with soy flour $[16,17,18]$. This observation can be attributed to the fact that cassava flour is a poor source of both proteins and fats and, therefore, its increased incorporation in bread making would undoubtedly result in correspondingly reduced amounts of proteins and fats. There were no significant differences in moisture contents in all the types of breads produced and this observation is due to the fact all the baked breads were subjected to the same baking conditions in the bread maker. The ash content of the breads was progressively increasing with increased cassava flour supplementation and the observed results are in line with a similar study where an increase in cassava flour supplementation in bread making resulted in a corresponding increase in ash content and that inorganic nutrients in the composite bread are richer than that of wheat bread $[19,20]$. Significant differences were only noted when comparisons were made between breads made from the $100 \%$ wheat flour and those with different substitution rates for both fermented and non-fermented cassava flour. However, when comparisons were made from breads made from the fermented and nonfermented cassava regardless of substitution rates, no significant differences were observed. 


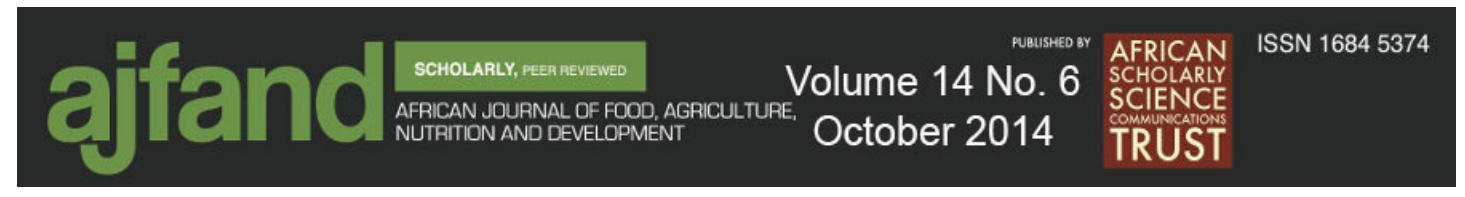

\section{Acceptability and index to volume}

From the results, acceptability and index to volume were both significantly affected by the type of the cassava flour used and the rate of cassava flour substitution in wheat-cassava flour blend. The results on acceptability agreed with those reported in previous related studies where it was found out that substitution levels of cassava flour obtained from citric acid treated tubers influenced overall acceptance of bread and overall acceptability scores decreased with an increase in cassava flour supplementation level for wheat-cassava composite biscuit enriched with soy flour $[21,22]$. The scores for index to volume decreased progressively with increased cassava flour supplementation and the bread made from $100 \%$ registered highest scores. However, bread made from fermented cassava flour had higher scores than bread made from the unfermented cassava flour and the reason might be attributed to the modification of the flour functionality properties as reported in a similar study where cassava flours produced from tubers which were steeped for 24 hours and treated with citric acid produced breads with improved quality characteristics [23]. Additionally, index to volume results were in contrast to other findings where it was reported that loaf height which is closely related to index to volume, loaf volume, oven spring and specific volume obtained from composite flours at $20 \%$ and $30 \%$ cassava substitution level and $1 \%$ malt were not significantly different to that of control bread obtained from 82\% extraction ratio wheat flour [24].

\section{CONCLUSION}

From the results, it can be concluded that cassava flour processing methods and substitution levels significantly affect the proximate composition, sensory characteristics and overall acceptability of bread made from wheat-cassava flour blends. Increased substitution level of cassava flour correspondingly reduced protein and fat contents in the breads while the ash content was increasing with increased cassava flour substitution level. Generally, index to volume scores were higher in substituted fermented cassava flour blends as compared to the unfermented cassava flour and a $10 \%$ substitution level in cassava flour is recommended for acceptable sensory attributes in breads made from wheat-cassava flour blends.

\section{Acknowledgements}

The authors wish to thank the management of Bunda College campus of the Lilongwe University of Agriculture and Natural Resources for financially supporting the study. We are also thanking all panelists who took part in the sensory evaluation and the laboratory staff in the departments of Food Science and Technology and Basic Sciences for their support in sample analysis. 


\section{Table 1: Mean scores for colour and aroma of bread}

Bread type based on cassava flour

type and level of cassava flour substitution

\section{Sensory characteristics score}

Colour

Texture

$100 \%$ wheat flour

$2.89 \pm 1.08^{\mathrm{a}}$

$2.29 \pm 1.06^{\mathrm{a}}$

Fermented flour: Wheat-cassava flour ratios

$\begin{array}{lll}90 \%: 10 \% & 2.62 \pm 0.91^{\mathrm{a}} & 2.58 \pm 1.09^{\mathrm{a}} \\ 80 \%: 20 \% & 2.47 \pm 0.79^{\mathrm{b}} & 3.02 \pm 1.14^{\mathrm{b}}\end{array}$

Unfermented flour:

$\begin{array}{lll}90 \%: 10 \% & 2.51 \pm 0.87^{\mathrm{b}} & 2.07 \pm 0.81^{\mathrm{a}} \\ 80 \%: 20 \% & 2.73 \pm 0.94^{\mathrm{ab}} & 2.62 \pm 1.17^{\mathrm{a}}\end{array}$

Means in the same column with different letters as superscripts are significantly different $(\mathrm{p}<0.05)$ 
Table 2: Mean scores for aroma and taste of bread

Bread type based on cassava flour

type and level of cassava flour substitution
Sensory characteristics score

Aroma Taste

$100 \%$ wheat flour

$2.24 \pm 1.11^{\mathrm{a}}$

$2.71 \pm 1.70^{\mathrm{a}}$

Fermented flour: Wheat-cassava flour ratios

$\begin{array}{lll}90 \%: 10 \% & 2.49 \pm 1.20^{\mathrm{a}} & 2.40 \pm 1.66^{\mathrm{a}} \\ 80 \%: 20 \% & 2.93 \pm 1.18^{\mathrm{b}} & 2.69 \pm 1.49^{\mathrm{a}}\end{array}$

Unfermented flour:

$\begin{array}{lll}\text { 90\%: } 10 \% & 2.22 \pm 0.88^{\mathrm{a}} & 3.96 \pm 2.06^{\mathrm{b}} \\ \text { 80\%: } 20 \% & 2.62 \pm 0.77^{\mathrm{a}} & 3.41 \pm 2.01^{\mathrm{a}}\end{array}$

$\overline{\text { Means in the same column with different letters as superscripts are significantly }}$ different $(\mathrm{p}<0.05)$ 


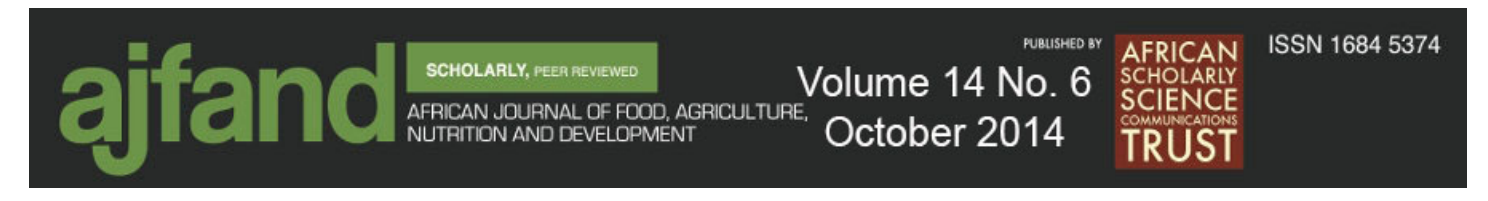

Table 3: Proximate composition of the bread (g/100g)

Bread type based on cassava flour

type and level of cassava flour substitution

$100 \%$ wheat flour

Fermented flour: Wheat-cassava flour ratios

$$
\text { 90\%:10\% }
$$

80\%: $20 \%$

Unfermented flour: $\quad 90 \%: 10 \%$

80\%: $20 \%$
$34.03 \pm 1.66^{\mathrm{a}}$

$11.20 \pm 0.10^{\mathrm{a}}$

$1.56 \pm 0.01^{\mathrm{a}}$

$1.65 \pm 0.16^{\mathrm{a}}$

\section{Proximate composition values}

Protein

Fat

Ash

\begin{tabular}{|c|c|c|c|c|c|}
\hline & 80\%: 20\% & $33.10 \pm 0.82^{\mathrm{a}}$ & $7.57 \pm 0.50^{\mathrm{c}}$ & $1.25 \pm 0.02^{\mathrm{c}}$ & $2.01 \pm 0.01^{b}$ \\
\hline Unfermented flour: & 90\%: 10\% & $30.53 \pm 0.32^{\mathrm{a}}$ & $10.10 \pm 0.50^{\mathrm{b}}$ & $1.29 \pm 0.02^{\mathrm{c}}$ & $1.96 \pm 0.01^{b}$ \\
\hline & $80 \%: 20 \%$ & $31.10 \pm 0.46^{\mathrm{a}}$ & $7.70 \pm 0.36^{c}$ & $1.26 \pm 0.02^{\mathrm{c}}$ & $2.01 \pm 0.01^{\mathrm{b}}$ \\
\hline
\end{tabular}




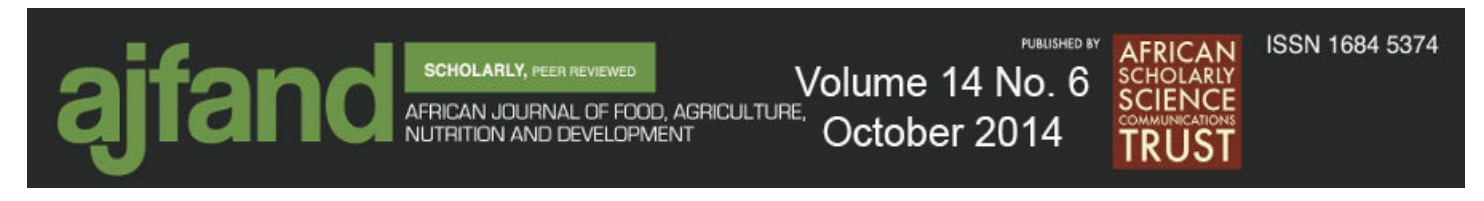

Means in the same column with different letters as superscripts are significantly different $(\mathrm{p}<0.05)$

Table 4: Mean scores for acceptability and index to volume

Bread type based on cassava flour

type and level of cassava flour substitution

Acceptability

Index to volume (mm)

$100 \%$ wheat flour

$2.67 \pm 1.40^{\mathrm{a}}$

$137.60 \pm 3.80^{\mathrm{a}}$

Fermented flour: Wheat-cassava flour ratios

$$
\text { 90\%:10\% }
$$

$3.26 \pm 1.3^{\mathrm{ab}}$

$122.80 \pm 3.10^{\mathrm{b}}$

80\%: 20\%

$2.89 \pm 1.30^{\mathrm{ab}}$

$108.80 \pm 3.70^{c}$

Unfermented flour: $\quad 90 \%: 10 \%$

$3.42 \pm 1.50^{\mathrm{b}}$

$105.80 \pm 4.70^{\mathrm{c}}$

80\%: 20\%

$2.70 \pm 1.30^{\mathrm{ab}}$

$93.80 \pm 3.70^{\mathrm{d}}$

Means in the same column with different letters as superscripts are significantly different $(\mathrm{p}<0.05)$ 


\section{REFERENCES}

1. Mayhew S and A Penny Tropical and sub tropical foods. London, United Kingdom, Macmillan Publishers, 1988.

2. Garrow JS, James, WPT and A Ralph Human Nutrition and Dietetics. $10^{\text {th }}$ edition, New York, USA, Churchill Livingstone, 2000.

3. Quaye W, Gavin J, Yawson I and W Plahar Characteristics of various cassava processing methods and the adoption requirements in Ghana. Journal of Root Crops. 2009; 35 (1): 59-68.

4. AOAC. Official Methods of Analysis of AOAC International. $14^{\text {th }}$ Edition. Edited by William S. The Association of Analytical Chemists, Inc. Arlington, Virginia, USA. 1984.

5. $\quad$ AOAC. Journal of AOAC International; 2002: 85 (2).

6. AOAC. Extraction of organic analytes from foods. A manual of methods. The Association of Analytical Chemists, Inc. Arlington, Virginia, USA. 1990.

7. Lawless HT and H Heymann Sensory Evaluation of Food. Principles and Practices. New York: Chapman and Hall. 1998.

8. Eddy NO, Udofia PG and D Eyo Sensory evaluation of wheat/cassava composite bread and effect of label information on acceptance and preference. African Journal of Biotechnology. 2007; 6 (20): 2415-2418.

9. FAO. Cassava processing: Starch and its uses. 2000. Retrieved on $15^{\text {th }}$ January, 2013 from www. fao.org/docrep/x5032e/x5032E06.htm.

10. Eddy NO, Udofia PG and D Eyo Sensory evaluation of wheat/cassava composite bread and effect of label information on acceptance and preference. African Journal of Biotechnology. 2007; 6 (20): 2415-2418.

11. Jusoh Y Effects of baking temperature, time and humidity on bread crust and crumb properties. Masters degree thesis, 2008. Retrieved on $7^{\text {th }}$ February, 2013 from www.psasiriupm.edu.my/5439/1/FK_2008_57a.pdf.

12. Gonani LD Quality of bread from different wheat and grain amaranthus flour blends. MSc. Thesis, University of Malawi, Bunda College of Agriculture, Lilongwe, Malawi. 2004.

13. Oluwamukoni MO, Oluwalana IB and OF Akinbowale Physicochemical and sensory properties of wheat-cassava composite biscuit enriched with soy flour. African Journal of Food Science. 2011; 5 (2): 50-56. 


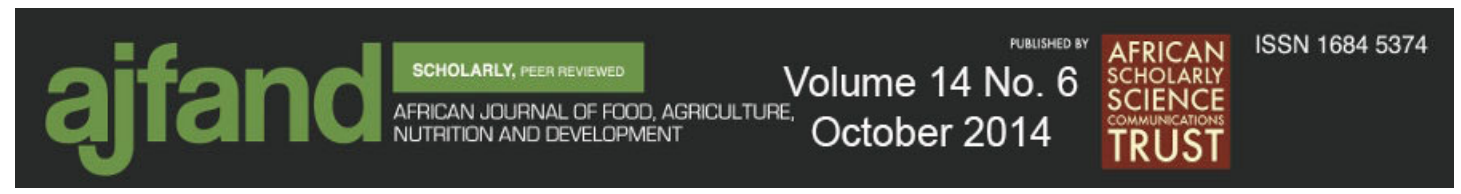

14. Eddy NO, Udofia PG and D Eyo Sensory evaluation of wheat/cassava composite bread and effect of label information on acceptance and preference. African Journal of Biotechnology. 2007; 6 (20): 2415-2418.

15. Dimple Singh-Ackbarali, Rohanie Maharaj Sensory Evaluation as a tool in determining acceptability of innovative products developed by undergraduate students in Food Science and Technology at the University of Trinidad Tobago. Journal of Curriculum and Teaching. 2012; 3(1): 10-27.

16. Oluwamukoni MO, Oluwalana IB and OF Akinbowale Physicochemical and sensory properties of wheat-cassava composite biscuit enriched with soy flour. African Journal of Food Science. 2011; 5 (2): 50-56.

17. Oyenuga VA Nigerian Food and Feeding stuffs. Ibadan University of Ibadan press, Nigeria. 1972.

18. Owuamanam CI Quality of bread from wheat/cassava composite as affected by strength and steeping duration of cassava in citric acid. Nature and Science. 2007; 5(4): 24-28.

19. Oluwamukoni MO, Oluwalana IB and OF Akinbowale Physicochemical and sensory properties of wheat-cassava composite biscuit enriched with soy flour. African Journal of Food Science. 2011; 5 (2): 50-56.

20. Kent NL and AD Evers Technology of cereals: An Introduction for students of food science and agriculture. $4^{\text {th }}$ edition. Pergamon, Great Britain. 1994.

21. Owuamanam CI Quality of bread from wheat/cassava composite as affected by strength and steeping duration of cassava in citric acid. Nature and Science. 2007; 5(4): 24-28.

22. Oluwamukoni MO, Oluwalana IB and OF Akinbowale Physicochemical and sensory properties of wheat-cassava composite biscuit enriched with soy flour. African Journal of Food Science. 2011; 5 (2): 50-56.

23. Owuamanam CI Quality of bread from wheat/cassava composite as affected by strength and steeping duration of cassava in citric acid. Nature and Science. 2007; 5(4): 24-28.

24. Khalil A, Mansour E and F Dawond Influence of malt on rheological and baking properties of wheat-cassava flour composite flours. LWT-Food Science and Technology. 2000; 33 (3): 159-164. 